\title{
Hotel Interdepartmental Communication: A Case of F\&B Service and Sales \& Marketing at Mercure Bandung Nexa
}

\author{
Musadad $^{1 *}$, Indria Angga Dianita ${ }^{2}$, Pradipta Dirgantara ${ }^{3}$ \\ ${ }^{1}$ Riau University \\ 2,3Telkom University \\ *musadad@lecturer.unri.ac.id
}

\begin{abstract}
This study sought to investigate the communication between the Food \& Beverage Department and the Sales \& Marketing Department at Mercure Bandung Nexa through the perspective of hotel interdepartmental communication. It was benefited from employing a qualitative method. The data collection was conducted through in-depth interviews with the managers of the two departments and field observations. The data collected was then analyzed and carried out through the elements of communication: people (sender and receiver), message, channel, noise, feedback, and effect. This study found that communication between the two departments goes well to keep the service excellent. Based on the analysis of the elements of communication, the only major obstacle is the sudden event that can disrupt the communication process. This result has brought discussion in the context of excellent service being delivered through the communication between the Food \& Beverage Department and Sales \& Marketing Department. However, this study is limited in the number of informants. More informants should be involved to gather more reliable and deeper data. After all, this study contributes to enriching the application of Interdepartmental Communication in organizations, especially in a hotel.
\end{abstract}

Keywords: Interdepartmental Communication, F\&B Service, Sales \& Marketing 


\section{A. Introduction}

Bandung is well known as a city of tourism in Indonesia because it is highly visited by local and foreign tourists. There are various types of tourism in the city, including nature tourism, man-made tourism, shopping tourism, and culinary tourism. Due to being visited by abundant tourists, the city has hotels to serve them, especially when they need accommodation.

With so many hotels in Bandung, the hotel business competition in the city is getting tougher. This spurs every hotel to survive and be able to compete with its competitors. The presence of new hotels makes hotel business owners have to increase resource productivity and improve the quality of service provided to guests to increase competitiveness. This has justified that to survive hotel business competition, the communication between departments must be improved. However, there is still limited research exploring the topics of interdepartmental communication particularly between the Food \& Beverage Department and the Sales \& Marketing Department.

A hotel is a company managed by its owner by providing dining, beverage, and bedroom facilities to people traveling and being able to pay a reasonable amount according to the services received without any special agreement. In hotels, the department in charge of serving guests in terms of food and beverages so that it plays a very important role in generating hotel revenue is Food and Beverages (F\&B) Service (Mertayasa, 2012).

The main function of the F\&B Service is to provide food and drink to guests (Nebel in Rutherford \& O'Fallon, 2011). Apart from hotels, this function can also be found in all walks of life, such as restaurants, company canteens, hospital canteens, airlines, and trains. The basic function of this department is to serve food \& drink to people and to meet their different types of needs. Along with its function, its main goal is to achieve customer satisfaction. In general, the duties and responsibilities of the F\&B Service are to ensure that the quality of service in the restaurant, room service, bar, cafe, lounge, and the coffee shop runs effectively and efficiently and generates positive business value.

To ensure the quality of this department is well implemented, all positions in this department require employees to always appear clean, friendly, polite, and courteous. Additionally, the employees also need to have fluent communication and language skills, enjoy interacting with other people, are agile and skilled, and have a high level of business and innovation in presenting a service to external and internal guests including maintaining the communication with the sales \& marketing department.

A seen from its job description, F\&B Service has intense communication with the sales \& marketing department. The sales \& marketing team also plays a vital role in hotel revenue. Moreover, the sales \& marketing team deals with the front office such as arranging rooms that to be sold, make room rates and manage rooms for meetings. Therefore, the sales \& marketing team must be able to pursue and archive the target and they usually deal with the group meeting guests.

Tourism Research Journal, Volume 5 (1), 2021 
The relationship between F\&B Service and Sales \& Marketing also occurs in terms of managing banquet events and arranging meeting rooms. However, there is a challenge related to the working relationship between the Sales \& Marketing Department and the banquet such as a lack of coordination between the Sales \& Marketing Department and the banquet which causes a loss for the hotel. This is in line with (Nebel in Rutherford \& O'Fallon, 2011) statement that coordination of activities must be run optimally to generate productive works in a hotel.

Communication, in this case, serves as an important aspect of the coordination of activities between departments. The coordination will not run effectively and efficiently once the communication is stuck or troubled. Hayes \& Ninemeier (2016) argue that communication is the key to solve the conflict between organizational levels. Furthermore, the sustainable hotel industry is strongly supported by the communication of the hotel staff and managers from which they have to be competent at verbal and non-verbal communication (Shen et al., 2020).

\section{B. Literature Review}

From a business and organizational perspective, effective communication is a must. Poor communication will result in quality problems, low productivity, and a lack of trust among individuals in the organization. Communication is defined by scholars as to the exchange of messages carried out between individuals to meet desired goals (Lolli, 2013). In a fast-rising industry such as hospitality, effective communication is essential to keep optimal productivity and performance (Mishra et al., 2014). Therefore, in general, communication is a process of forming, conveying, receiving, and processing messages that occurs within a person and or between two or more with a specific purpose.

Communication does not only mean transferring messages, but also comprises how people use messages to generate meaning in and across varied cultures, channels, contexts, and media (Keyton, 2017). Therefore, communication will be effective once there is an exchange of information to form a denotation to be received and understood pleasingly. Most scholars defined communication as the process of transferring messages which have a piece of particular information from a source to a recipient (O'Hair et al., 2012). Therefore, to promote improved productivity and keep it robust, working relationships can be achieved through effective communication so that it can increase an organization's competitiveness (Stacho et al, 2019).

To create effective communication, a communicator should understand the elements of communication. These elements enable communication to run smoothly and effectively. According to Gamble \& Gamble (2012), the elements of communication include people (sender and receiver), message, channel, noise, feedback, and effect. The elements in a process of communication will also define the communication's quality (Adu-Oppong, 2014). To have a successful operational quality within an organization, strategic communication has to be possessed and applied by the management and the staff (Seyitoglu \& Yuzbasioglu, 2015).

Tourism Research Journal, Volume 5 (1), 2021 
The difference between this study and previous research is how to describe the communication that occurs between the F\&B and Sales \& Marketing departments. After seeing whether the communication is going well or not, this study identifies the factors that cause it so that the results of this study can be a reference for other hotel management in managing communication between departments. To provide a better focus, this study is limited to the scope of communication that occurs between the two departments at Mercure Bandung Nexa (Hotel Nexa).

\section{Research Methodology}

This study employed a qualitative research method with a narrative approach. According to Creswell (2012), the procedure for performing this type of research includes focusing on one or 2 individuals, collecting data through their stories, reporting their experiences, and sorting the meaning of their experiences.

The data were collected through observation and interviews with managers of the F \& B Service and Sales \& Marketing Department. This study used a structured in-depth interview with open-ended questions. Meanwhile, this study used a nonparticipant observation where the researcher only observed and was not involved in the field activities. To validate the data, this study used a data source triangulation through different informants, i.e. a manager of the $\mathrm{F} \& \mathrm{~B}$ department and a manager of the Sales \& Marketing department, and a method triangulation by collecting data through different methods, i.e. observation and interview (Denzin \& Lincoln, 2011).

After the data collection, the results of the interview were then transferred to the transcripts and then analyzed. Saldana (2011) states that there is no standardized method in qualitative data analysis, but there are several suggested ways to reconstruct meaning manually or with the help of technology. In analyzing the data, this study sorted the data from the collected information and then constructed the meaning of the information (Saldana, 2011).

\section{Results}

Nexa Hotel is a 4-star business hotel located at Jalan WR Supratman No. 6668 Bandung, West Java. It has 181 rooms and suites, 8 meeting rooms and other facilities. The hotel has a Sales \& Marketing Department which is competent in selling the hotel products. It is proven that even though it was only established in 2015, the hotel has managed to position itself in the top 10 of TripAdvisor and always has a high occupancy every month. The Sales \& Marketing Department at Nexa Hotel always uses an effective marketing communication strategy in selling its products.

In its operation, the Sales \& Marketing department must coordinate with the F\&B Department. The relationship between the two departments occurs when the F\&B Department assists the Sales \& Marketing Department in the sale of banquet products and also assist in these productions to increase hotel revenues (Mertayasa, 2012). The managers of the two departments at Nexa Hotel confirmed this. Based on the interview this close relationship has brought the two departments to coordinate with each other. To ensure the coordination becomes effective and efficient, there

Tourism Research Journal, Volume 5 (1), 2021 
Hotel Interdepartmental Communication: A Case of F\&B Service and Sales $\&$ Marketing at Mercure Bandung Nexa

must be well-established communication between the two. The communication takes place in a communication process involving six elements of communication (Gamble \& Gamble, 2012).

\section{Communication between F\&B Department and Sales \& Marketing Department}

Based on the interviews and field observations with the managers in the relationship between the two departments, the frequency of the communication initiation mostly comes from the Sales \& Marketing department, although the F\&B Department also initiates the communication. This is because the Sales \& Marketing team must inform the $\mathrm{F} \& \mathrm{~B}$ team or ensure that the booked events can be organized well.

After an event is booked by guests and confirmed by the hotel as represented by the Sales \& Marketing department, a Banquet Event Order (BEO) is made for the internal hotel necessity. BEO is a form describing the theme, the time and date, and the number of guests of a booked event. It also lists food and beverages ordered by guests and the type of banquet room that will be used. Furthermore, BEO is distributed to related sections such as kitchen, housekeeping, engineering, restaurant, security, front office.

\section{Elements in the Communication Process}

According to Gamble \& Gamble (2012), the elements of communication include people (sender and receiver), message, channel, noise, feedback, and effect. From these elements, the analysis of the communication process happened between the F\&B and Sales and Marketing Departments is as follows:

1. People

Every communication process involves humans who are the sender and receiver of the message. In the people element, the communicating parties can be divided into receivers and senders. This means that both the F\&B Department and Sales $\&$ Marketing Department can become the sender and the receiver. Those involved in the communication include staff and managers from the two departments. From the F \& B Department, it includes manager, assistant manager, head waiter, and staff, while from Sales and Marketing department it includes sales executive, assistant sales manager, sales manager, and director of sales. These people are indicated from the hotel's document (organizational structure) and the manager's statement:

"In F\&B department, we have manager, assistant manager, head waiter, and staff. In Sales and Marketing department, we have executive, assistant sales manager, sales manager, and director of sales". These people are those involved in the communication between the F\&B department and the Sales and Marketing department. They perform daily intense communication as these two departments are very closely related to each other as they cooperate in serving guests and arranging orders or promotional programs.

Tourism Research Journal, Volume 5 (1), 2021 
Hotel Interdepartmental Communication: A Case of F\&B Service and Sales $\&$ Marketing at Mercure Bandung Nexa

2. Message

The message is information that the sender wants to convey to the recipient. The message element in this study is divided into two which consists of messages from the F \& B Department to the Sales \& Marketing Department and vice versa, the messages from the Sales \& Marketing Department to the F \& B Department. Messages conveyed from F\&B Department to Sales \& Marketing Department include comments from Person in Charge (PIC) regarding events, the update of any progress that has been made, and changes in the arrangement of guests outside of BEO. Meanwhile, messages from the Sales \& Marketing Department to F\&B Department include payment method, layout, the number of participants, rundown of each event, special request, and set up menu. These messages are shown by the manager's statement:

"We communicate about comments from PIC regarding events, updates on any progress that has been made. Changes in the arrangement of guests outside of BEO (Banquet Event Order." "We communicate about payment methods, Layout, the quantity of participants, the rundown of each event, special requests, menu set up." From the above transcripts, it can be inferred that both the F\&B department and marketing \& sales department have to communicate various things, which, of course, are vulnerable to misperception and misunderstanding. As a consequence, the managers should have an effective program to have an interaction with minimum errors.

3. Channel

Humans can send and receive messages in various ways as well as receiving media, for example, through sensory organs. They can also communicate verbally and non-verbally. This is called a channel which is generally defined as through what and how the message is conveyed and received. At Nexa Hotel, the channels used to communicate between F\&B and Sales \& Marketing Departments include written media such as BEO, Email, WhatsApp Messages, to communicate something not urgent, verbal media like telephone and direct communication when coordinating meetings, and by a system such as using the POS to comprehend forecasted events and updated revenue. Concerning these, the manager admitted that:

"We communicate using BEO, Email, WA, Telephone and direct communication (coordination meeting), using the POS application to determine forecast events and update revenue." When referring to the communication channels as proposed by Terzic \& Ascic (2017), communication between the F\&B department and sales \& marketing department has utilized both written and oral channels. The written channels include BEO, Email, WA, and POS software, while the oral channels include Telephone and direct communication.

4. Noise

Noise means the disturbances or obstacles that arise and reduce the ability to send and receive messages maximally. In terms of noises or communication distractions, the manager admitted that:

Tourism Research Journal, Volume 5 (1), 2021 
Hotel Interdepartmental Communication: A Case of F\&B Service and Sales $\&$ Marketing at Mercure Bandung Nexa

"We experience slow response in the process for communication with WA Chat/Group)" (from F\&B Service to Sales \& Marketing Department).

"By using BEO (Banquet Event Order), as long as there are no sudden changes, overall, it is very effective" (from Sales \& Marketing Department to F\&B Service). From the above transcript, it can be concluded that, at Nexa Hotel, noise is divided into two based on sender and receiver described as follows:

a. Noise in communication from F\&B Department to Sales \& Marketing Department: slow response in the process (for communication using WhatsApp Messages)

b. Noise in communication from Sales \& Marketing Department to F\&B Department: sudden changes on BEO can disrupt the communication process. However, when there are no sudden changes, the noise is toned down and the communication is overall very effective.

5. Feedback

Feedback is given by the recipient to the sender after receiving a message. From this feedback, the message's sender can see whether the sent message is received well by the recipient as desired by the sender or not. Feedback in communication between F\&B Department and Sales \& Marketing at Nexa Hotel will get slower when the message is considered not urgent or when the message is delivered using WhatsApp Messages. However, the feedback will be fast when the message is displayed with a high level of urgency like coordinating guest meetings or when the message is delivered using a phone and direct communication response. However, the F\&B Manager stated that:

"Yes (there are differences), but still reasonable. Because the F\&B team also understands the conditions of the sales team who might be out of the office or having a meeting with clients. (But) If it is urgent, the leader from the F\&B will immediately phone the sales team."

Thus, if the response is slow, it is still reasonable and manageable. This is because the F\&B team understands the conditions of the Sales \& Marketing team who may be having business activities or interacting with clients. Nevertheless, when it is urgent, the F\&B leader will immediately call the sales \& marketing team to get a fast response or immediate direct feedback.

6. Effect

Effect means the result of interaction in the communication process. Communication effect is the influence of the communicator's message in the communicant. Concerning the communication effects, the manager said that:

"Positively all events can be performed with a relatively short preparation time, both parties are more interactive in the preparation, reducing the risk of unnecessary mistakes, maximizing all guest needs in a short time, and all conversations are recorded in the WA group. Meanwhile, negatively, sudden events have caused non-maximal preparations."

According to Gamble \& Gamble (2012), communication has three effects, namely cognitive, affective, and conative. The effects that occur in communication

Tourism Research Journal, Volume 5 (1), 2021 
between F\&B and Sales \& Marketing Department at Nexa Hotel include as follows:
a. Cognitive effect
Both parties understand the process of completing work better, especially when there is an event.
b. Effective effect
Both parties are more interactive in their preparation.
c. Conative effect
All events can be performed although the preparation time is relatively short.

\section{E. Discussion}

The communication between the F\&B Department and the Sales \& Marketing Department of the two departments goes well because the two have established effective communication since the hotel was built. The manager admitted that he was satisfied with the communication in his department. As found by Dawson et al (2012), communication satisfaction constitutes a significant and important aspect of work outputs in the hotel industry. The nature of the two departments in hotel service which brings them into a close relationship at work also plays a major part in coordinating and delivering communication. Because of this, they can fulfill the guests' requests through $\mathrm{BEO}$.

It is understandable when the Sales \& Marketing Department has a bigger part in initiating the communication because they face directly with the guests' requests. However, the delivery of information from the Sales \& Marketing Department as a sender is carried out well and as the result, the message is received comprehensively by the F\&B Department as a receiver. The means of communication between the two relies on the $\mathrm{BEO}$ and the message between them is exchanged through different channels such as emails, phone calls, or WhatsApp messages depending on the urgency. The sudden changes should be anticipated by talking out to the guests and ensuring their requests or making the communication more reliable. In the end, they use all communications means possible to ensure to fulfill $\mathrm{BEO}$ or guests' requests on booked events.

The results showed that the communication between the F\&B department and the sales \& marketing department ran smoothly without any significant interruptions. The factors that facilitate communication at Nexa Hotel are as follows:

1. Feeling Trust

A sense of trust between colleagues. A sense of belief that everything that the whole team does is the best.

2. Feeling Valued

Every job or task that gets done well is rewarded. Example: Saying thank you (the simplest).

3. Helping Each Other

Helping each other between departments, especially in the COVID-19 pandemic in which many employees are laid off. As a result, the two departments must

Tourism Research Journal, Volume 5 (1), 2021 
complement each other if there is a department in need. Example: Sales Team helps serve food when serving guests at a buffet.

4. We are One

Every employee is considered a family so it is natural and reasonable to help each other. They complement and strengthen each other.

\section{F. Conclusion}

The results of the data analysis indicate that the communication process between the F\&B Department and Sales \& Marketing Department at Hotel Nexa Bandung has no meaningful obstacles. The only issue in the communication process is suddenness meaning communication will get some trouble when both departments are in a rush in the appearance of sudden changes from guests' requests. This is because they will only have limited time to finish their work so that miscommunication sometimes happens. Hence, it can be concluded that the communication process between the two departments is going well so far. This cannot be separated from the role of management which always stresses that all employees must trust each other, respect each other, and help each other.

This study is limited in the number of informants. There should be more informants involving directly in the communication between the two departments than the informants collected in this study. They may be employees, supervisors, and the managers of each department. Further studies need to vary their informants and conduct in-depth analysis for each element of communication.

\section{G. Acknowledgement}

The authors would like to express their gratitude to the management of Mercure Bandung Nexa (Nexa Hotel) Bandung who was willing to provide data and information for the completion of this study.

\section{REFERENCES}

Adu-Oppong, A. (2014). Communication in the Workplace: Guidelines for Improving Effectiveness. Global Journal of Commerce \& Management Perspectives, 3(5): 208-213.

Creswell, J. W. (2012). Qualitative Inquiry and Research Design Choosing among Five Approaches. London: Sage Publications, Inc.

Dawson, M., Madera, J., Neal, J. A., \& Chen, J. (2012). The Influence of Hotel Communication Practices on Managers' Communication Satisfaction with Limited English-Speaking Employees. Journal of Hospitality and Tourism Research, 38(4): 545-561.

Denzin, N., \& Lincoln, Y. (2011). Qualitative Research. London: Sage Publications, Inc.

Gamble, T. K., \& Gamble, M. W. (2012). Communication Works. New York: McGrawHill Education.

Tourism Research Journal, Volume 5 (1), 2021 
Hayes, D. K., \& Ninemeier, J. D. (2016). Human Resource Management in the Hospitality Management. New York: John Wiley \& Sons.

Keyton, J. (2017). Communication in Organizations. Annual Review of Organizational Psychology and Organizational Behavior, 4(1): 501-526.

Lolli, J. (2013). Interpersonal communication skills and the young hospitality leader: Are they prepared?. International Journal of Hospitality Management, 32: 295-298.

Mertayasa, I G. A. (2012). Food and Beverage Service Operational Job Preparation. Yogyakarta: Andi.

Mishra, K., Boynton, L., \& Mishra, A. (2014). Driving Employee Engagement: The Expanded Role of Internal Communications. International Journal of Business Communication, 51: 183-202.

O'Hair, D., Fredrick, G. W., \& Dixon, L. D. (2012). Communication in Business. Boston: Houghton Mifflin.

Rutherford, D. G., \& O'Fallon, M. J. (2011). Hotel Management and Operations. New Jersey: John Wiley \& Sons.

Saldana, J. (2011). Fundamentals of Qualitative Research. New York: Oxford University Press.

Seyitoglu, F. and Yuzbasioglu, N. (2015). The Role of Strategic Communication in Hospitality Industry "The Case of Antalya". Journal of Social Science Studies, 2(2), 16-35.

Shen, L., Qian, J., \& Chen S. C. (2020). Effective communication strategies of sustainable hospitality: A qualitative exploration. Sustainability, 12(6920): 1-14.

Stacho, Z., Stachová, K., Papula, J., Papulová, Z., \& Kohnová, L. (2019). Effective Communication in Organizations Increases their Competitiveness. Polish Journal of Management Studies, 19: 391-403.

Terzic, E. and Ascic, A. (2017). Modern communication channels in function of improving management. The International Conference "Economics and ManagementBased on New Technologies" EMoNT-2017. 